\author{
Religion Causes Decreases in Women's Provocativeness of Dress \\ Liana S. E. Hone ${ }^{\mathrm{a}, \mathrm{b}}$ \& Michael E. McCullough \\ aDepartment of Psychology, University of Miami \\ ${ }^{\mathrm{b}}$ Clinical and Research Institute on Addictions, University at Buffalo
}

Author Note

Preparation of this manuscript was supported in part by grant F32 AA025830 from the National Institutes of Health (PI: Liana S.E. Hone).

Correspondence concerning this article should be addressed to Liana S.E. Hone.

Contact: lhone@buffalo.edu. 


\begin{abstract}
Long-term mating strategies are associated with greater religiosity and studies demonstrate that exposure to religious stimuli down-regulate traits associated with short-term mating strategies in men. Based on evidence that women might also occasionally pursue shortterm mating strategies, we evaluated the effects of religiosity on a trait associated with women's mating strategies: Provocativeness of dress (POD). We predicted that women's baseline religiosity would be negatively correlated with their POD (measured via skin exposure) on the premise that POD is typically associated with women's short-term mating strategies. We also predicted that women who completed a religious writing task would illustrate less skin exposure than their peers when asked what they would wear to a hypothetical social gathering with attractive members of the opposite sex in attendance. In a college sample of 817 participants, women (but not men) who classified themselves as highly religious exposed less skin in their day-to-day lives. Likewise, women (but not men) who completed a religious writing task illustrated less skin exposure than did their peers. A significant religiosity by writing task condition assignment interaction indicated that the religious writing task was more effective in reducing skin exposure for highly religious participants than it was for less religious participants. Keywords: religion, provocativeness of dress, mating strategies; sexual strategies; sex differences
\end{abstract}




\section{Religion Causes Decreases in Women's Provocativeness of Dress}

Several individual differences in characteristics such as age (Kenrick \& Keefe, 1992) 1992), personality (Pines, 1998), and sociosexual orientation (Provost, Troje, \& Quinsey, 2008) influence the mating strategies that men and women pursue. Recently, research has evaluated the utility of religiosity in long-term mating strategies (Moon, Krems, Cohen, \& Kendrick, 2019) because religiosity is a known predictor of restricted sexual attitudes, behaviors, and fantasies (Aalsma et al., 2013; Ahrold, Farmer, Trapnell, \& Meston, 2011) associated with long-term orientations. That is, Reproductive Religiosity Theory posits that people strategically use their religious beliefs, religious attendance, and religious group affiliations to support a long-term mating strategy, and to buffer against the costs affiliated with this mating strategy (Weeden, Cohen, \& Kenrick, 2008; Weeden \& Kurzban, 2013).

This theory is based on the observation that people who pursue long-term strategiescharacterized by high levels of commitment to one's partner and high levels of parental investment - are undermined by sexual rivals who pursue short-term mating strategies marked by sexual promiscuity, male abandonment, and female cuckoldry (Weeden et al., 2008).

Religion's adherents, who actively promulgate social norms that encourage fidelity and condemn promiscuous conduct, can help mitigate the risks associated with long-term mating strategies by causing others to adopt a restricted strategy or forcing them to seek out their partners in other mating pools (Weeden et al., 2008). Religious groups might also facilitate monogamy and parental investment by providing reproductive support to families (Weeden et al., 2008; Weeden \& Kurzban, 2013). Supporting this idea, religiosity is linked to reduced number of sexual partners (Twenge, Sherman, \& Wells, 2015) and reduced rates of cuckoldry (Strassmann et al., 
2012), as well as reduced unrestricted sexual behaviors like viewing pornography (Wright, 2013).

In line with these observations, religions' adherents tend to be viewed as trustworthy (Hall, Cohen, Meyer, Varley, \& Brewer, 2015; McCullough, Swartwout, Shaver, Carter, \& Sosis, 2016; Tan \& Vogel, 2008) and this trustworthiness is linked to perceived reproductive strategies (Moon, Krems, \& Cohen, 2018; Moon et al., 2019). That is, people tend to trust religious targets more than nonreligious targets because of their supposed adherence to long-term mating strategies, including more restricted sexual orientations and reduced sexual promiscuity, male abandonment, and female cuckoldry.

Evidence of a link between religiosity and mating strategies has been found across several major regions of the world, with personal religiosity associated with lower permissive sexuality in North and South America, Western, Eastern, and Southern Europe, the Middle East, Africa, Oceania, and South/Southeast and East Asia (Schmitt \& Fuller, 2015). Several large studies conducted in the contemporary United States (Weeden et al., 2008) and 90 additional countries (Weeden \& Kurzban, 2013) have confirmed these predicted patterns regarding the relationship between religiosity and sexual and family lifestyle variables related to mating strategies. These include studies of 21,131 adults in the 2006 United States General Social Survey, 902 college students from four universities in the United States, and 296,959 participants from 90 countries in the World Values Survey (Weeden et al., 2008; Weeden \& Kurzban, 2013).

Using Reproductive Religiosity Theory as a theoretical framework, researchers have tested whether people might become more religious when attractive, same-sex competitors, are made salient (Li, Cohen, Weeden, \& Kenrick, 2010). Indeed, women who viewed dating profiles of attractive women, and men who viewed dating profiles of attractive men reported higher 
levels of religiosity than did those who viewed dating profiles of opposite-sex peers.

Furthermore, men who viewed men, and women who viewed women increased in religiosity.

That is, when attractive, same-sex competitors are made salient, participants describe themselves as more religious than participants in control conditions. Thus, it seems variations in religiosity are linked to mating strategies in experimental paradigms.

If it is the case that people put their religious beliefs and group affiliations to strategic use to support long-term mating strategies, then exposure to cues associated with religious environments should down-regulate the expression of traits associated with short-term strategies (McCullough, Carter, DeWall, \& Corrales, 2012). Examples of traits associated with men’s short-term mating strategies include outlays of physical endurance, risky demonstrations, and unwillingness to delay gratification (Archer, 2009; Daly \& Wilcon, 2005; Hawkes, 1991; Kirby \& Maraković, 1996; Little \& Johnson, 1986; Pawlowski, Atwal, \& Dunbar, 2008; Shih, 2007; Silverman, 2003; Wilson \& Daly, 2004). In line with this rationale, research shows that men primed with religion were more willing to delay gratification and also display reduced outlays of physical endurance than men who were not primed with religion (McCullough et al., 2012; c.f. Hone \& McCullough, 2014). Taken together, cross-cultural evidence of a link between religiosity and restricted sexuality (Schmitt \& Fuller, 2015), cross-sectional evidence from large studies (Weeden et al., 2008; Weeden \& Kurzban, 2013), as well as experimental evidence (Li et al., 2010; McCullough et al., 2012), suggest that mating strategies and religiosity are tightly linked.

\section{Study Rationale}

Whereas experimentally manipulating religious salience might indeed down-regulate the expression of traits associated with short-term strategies in men, the intermediate variables that 
link mating strategies to religion and behavior in women are largely unexplored. If people do put their religious beliefs and religious group memberships to strategic use to support long-term mating strategies, and if women sometimes enact short-term strategies (Buss \& Schmitt, 1993), perhaps certain sexually selected, characteristically female behaviors might be subject to downregulation upon exposure to religious stimuli. Based on (1) theorizing that long-term mating strategies are associated with greater religiosity (Li et al., 2010; Weeden et al., 2008), (2) studies demonstrating that exposure to religious stimuli down-regulates characteristics associated with short-term mating strategies in men (McCullough et al., 2012), and (3) evidence that women might sometimes pursue short-term mating strategies (Buss \& Schmitt, 1993), a study evaluating the effects of religiosity on provocativeness of dress (POD), a trait associated with religiosity (Davis, 2017) and short-term mating strategies in women (Grammer, Renninger, \& Fischer, 2004), would provide insight into the association of religiosity and mating strategies. The purpose of this study was to examine the potential causal nature of the association between religiosity and POD.

\section{Predictions}

Based on cross sectional evidence that long-term mating strategies are associated with greater religiosity, we predicted that women (but not men) who classified themselves as highly religious (regardless of religious group affiliation) would expose the least amount of skin. That is, women's (but not men's) religiosity scores would be negatively correlated with skin exposure in photographs of what they wore to the laboratory. Furthermore, based on studies demonstrating that exposure to religious stimuli can down-regulate characteristics associated with short-term mating strategies, we predicted that women who were exposed to religious stimuli would expose the least amount of skin. That is, women (but not men) assigned to a religious writing task 
condition would illustrate less skin exposure than their peers who were not assigned to a religious writing task condition, when asked what they would wear to a hypothetical social gathering.

\section{Method}

\section{Participants}

Participants were 817 students (440 women) at the University of Miami aged 17 to 48 $($ Median $=19, M=19.14, S D=2.18)$ enrolled in Introduction to Psychology from fall of 2012 to spring of 2014 .

\section{Procedure}

Mixed sex groups of up to four participants at a time completed a one-hour laboratory session. The laboratory session comprised standing for a photograph and completing a writing task, an illustration task, and a questionnaire. Upon arrival at the laboratory, participants were escorted to a room in which a Panasonic digital camera (Lumix DC Vario) was set up on a tripod and placed five feet from a mark behind which participants stood to have their photograph taken. Subjects were told to stand with the tips of their toes behind a line and keep their hands to their side. They were told to try to relax, try not to smile, and try to keep their eyes on the mark on the wall behind the research assistant. After the photo, subjects received an envelope containing a writing task, a standardized mannequin illustration task, and a questionnaire including several measures, all detailed below. Research assistants were blind to subjects' condition assignment.

Once participants' photographs were taken, they were taken to a room to complete the tasks and questionnaires and told to take out the writing task, which would be timed. The research assistant then used a stopwatch to time the 15-minute writing task. When 15 minutes had passed, research assistants told participants to stop and put the writing task back in the 
envelope. Next, research assistants handed subjects a set of colored pencils for the standardized mannequin illustration task. The research assistant then told participants to complete the untimed illustration task, followed by the untimed questionnaire. When all of the subjects in each session were finished, research assistants collected subjects' envelopes and thanked them for their cooperation. Research assistants remained blind to subjects' condition assignment for the duration of the experimental session.

Writing task. During their experimental session, participants were randomly assigned to complete one of three writing tasks (religious, secular, control) designed after (McCullough et al., 2012). The instructions for the religious version of the writing task (see Appendix A) stated: "For the next 15 minutes, we'd like for you to write an essay about your beliefs and feelings about God and/or your religion. Please focus on your connection to God and/or your religion, what it means to be a member of your religion and the aspects of your religious beliefs and practices that mean the most to you. If you are not a religious person, please write about what the idea of God means to you. Please be as detailed as you can. If you have time left before the 15 minutes are over, please continue writing about the same topic, even if you feel like you are repeating yourself." The instructions for the non-religious writing tasks prompted participants to write about their country and culture (secular condition) or objects in their dorm or house (control condition). Participants were given approximately two $8 \frac{1}{2}$ by 11 -inch blank pages on which to write for fifteen minutes.

Illustration task. After completing the writing task, women received a blank standardized mannequin of a female figure as in Durante, Li, \& Haselton (2008) and prompted with the following instructions: "Imagine that you are attending a social gathering at a friend's apartment tonight around 10:30 PM. From what your friend tells you, it will be a large party 
where there will be lots of single attractive people. Using the colored pencils provided, indicate on the outline of the human figure (on the next page) what you will be wearing to this party by drawing an outfit. Be sure to show the outlines of each item of clothing-your shirt, pants, shorts, skirt, etc.—clearly" (see Appendix B). Men were given a standardized male mannequin and given the same instructions (see Appendix C).

\section{Experimental Session Measures}

After finishing their illustrations on the blank standardized mannequin, participants completed the questionnaire, which included demographic items, an option to select their religious group affiliation, and the 10-item Religious Commitment Inventory (RCI) (Worthington et al., 2003).

Demographics. The demographic portion of the questionnaire included items pertaining to participants' sex, age, and sexual orientation. Sexual orientation was measured via a Likerttype item, "Please check the single option that best describes your sexual orientation," on a seven-point scale from 0 (Exclusively heterosexual) to 6 (Exclusively homosexual).

Religion. Participants chose one of several mutually exclusive labels (Atheist, Baptist, Buddhist, Catholic, Christian, Christian Reform, Church of God, Congregational/United Church of Christ, Disciples of Christ, Agnostic, Episcopalian/Anglican, Evangelical/Born Again, Hindu, Humanist, Jehovah's Witness, Jewish, Lutheran, Methodist/Wesleyan, Muslim, Nondenominational, Orthodox (Eastern), Pentecostal/Charismatic, Protestant, Presbyterian, Reformed/Dutch Reform Seventh-Day Adventist, Spiritualist, Unitarian/Universalist, some other religion, or two or more religions).

Religiosity. Some past researchers have used religiosity as a moderator of effects of religious primes in past studies (Billingsley, Gomes, \& McCullough, 2018; McKay, Efferson, 
Whitehouse, \& Fehr, 2011; Randolph-Seng \& Nielsen, 2007; Shariff \& Norenzayan, 2007).

Because the current study used a religious writing task that required religious and non-religious subjects alike to write about what the idea of God means to them, we included the Religious Commitment Inventory (RCI; Worthington et al., 2003). The 10-item RCI consists of items such as "I spend time trying to grow in understanding of my faith," and "Religious beliefs influence all my dealings in life," which subjects endorsed on a scale from 0 (not at all true of me) to 4 (completely true of me; see Appendix D). We calculated the mean of the scores on the $10 \mathrm{RCI}$ items to create a composite religiosity score (Cronbach's alpha $=.93$ ).

\section{Post-Experimental Session Measures}

After the experimental session, mean daily temperature was recorded and skin exposure of the photographs and standardized mannequin illustrations were computed.

Mean daily temperature. Using the Old Farmer's Almanac (2015), we recorded the mean outside daily temperature (in degrees Fahrenheit) for the day of each subjects' laboratory visit (Almanac, 2015). We converted the recorded temperatures to degrees Celsius.

Skin exposure. To calculate skin exposure in the photographs, raters imported digital photographs into Adobe Photoshop. Using the "Quick Selection Tool," two raters recorded the total number of pixels of participants' bodies and the number of pixels of skin exposed in the photographs. The intraclass correlation between the two raters' photograph assessments of skin exposure was 0.99 . For each participant, we calculated a mean of the two raters' recordings of the number of pixels of skin exposed in the photographs. We then calculated a ratio of the mean number of pixels of exposed skin to the total pixels of the participants' bodies in the photographs (the total number of pixels of participants' bodies varied by participant). 
To calculate skin exposure in subjects' hand-drawn illustrations on a standardized mannequin of what they would wear to a hypothetical night-time social gathering, raters imported scanned illustrations into Adobe Photoshop. Using the "Quick Selection Tool," two raters recorded the total number of pixels of skin exposure in their mannequin illustrations. The intraclass correlation between the two raters' estimates from the standardized mannequins was 0.98. For each participant, we calculated a mean of the two raters' recordings of the number of pixels of skin exposed in the illustrations. We then calculated a ratio of the mean number of pixels of exposed skin to the total number of pixels in the mannequins (the total number of pixels of participants' mannequin was standard).

\section{Results}

Demographics. Of the women who reported their sexual orientation, 378 identified themselves as exclusively heterosexual, 56 as heterosexual/homosexual, and 3 as exclusively homosexual. Among the men, 351 identified themselves as exclusively heterosexual, 17 as heterosexual/homosexual, and 6 as exclusively homosexual. Exclusively heterosexual women and men did not expose more skin than their same-sex peers who were not exclusively heterosexual.

Religion. Of the women who reported their religious affiliation, 122 identified themselves as Christian, 66 as Nonaffiliated, 65 as Other, 123 as Catholic, and 53 as Jewish. Eight women declined to answer. Among the men, 84 identified themselves as Christian, 90 as Nonaffiliated, 59 as Other, 89 as Catholic, and 50 as Jewish. Five men declined to answer. Christians, Catholics, Jews, and Others showed similar skin exposures.

Religiosity. Women scored higher on the 10-item Religious Commitment Inventory than did men. Exclusively heterosexual women's religiosity scores were significantly higher than 
were those of non-exclusively heterosexual women. Likewise, exclusively heterosexual men's religiosity scores were higher than those of non-exclusively heterosexual men. Excluding nonheterosexual participants did not change the results detailed below. Christians, Catholics, Jews, and Others showed similar religiosity scores and religiosity scores did not differ between participants in the religious, secular, and control writing task conditions.

\section{Baseline Religiosity and Photographed Provocativeness of Dress}

We conducted a multiple regression analysis to predict photograph skin exposure from mean daily temperature, sex, and religiosity scores. Mean daily temperature, sex (dummy-coded with women as the reference group), religiosity scores, and the religiosity scores by sex interaction were entered in the model. Mean daily temperature, sex, religiosity scores, and the religiosity scores by sex interaction accounted for a significant amount of photograph skin exposure variability (see Table 1). For women, as religiosity scores increased, skin exposure decreased (see Figure 1a). No such relationship between religiosity scores and skin exposure existed for men (see Figure 2 b). Together, these variables accounted about $22 \%$ of the variance in photograph skin exposure.

\section{Table 1}

Regression results using photograph of what participants wore to the laboratory as the criterion.

$$
\text { 95\% CI for } b \quad \text { Correlations }
$$

\begin{tabular}{lcccccccccc} 
Predictor & $b$ & SE & Beta & $t$ & $p$ & $L L$ & $U L$ & $r$ & Partial & Part \\
& & & & & & & & & & \\
\hline Constant & -8.30 & 3.92 & & -2.12 & 0.03 & -15.99 & -0.62 & & & \\
${ }^{\circ} \mathrm{C}$ & 0.76 & 0.08 & 0.32 & 10.01 & $<\mathbf{0 . 0 0 1}$ & 0.61 & 0.91 & 0.30 & 0.34 & 0.31 \\
Sex & -7.94 & 0.75 & -0.33 & -10.59 & $<\mathbf{0 . 0 0 1}$ & -9.42 & -6.47 & -0.32 & -0.35 & -0.33
\end{tabular}




$\begin{array}{lcccccccccc}\text { RCI } & -2.05 & 0.48 & -0.18 & -4.31 & <\mathbf{0 . 0 0 1} & -2.99 & -1.12 & -0.09 & -0.15 & -0.14 \\ \text { Sex by } & 1.77 & 0.75 & 0.10 & 2.37 & \mathbf{0 . 0 2} & 0.31 & 3.23 & 0.00 & 0.08 & 0.07 \\ \text { RCI } & & & & & & & & & & \end{array}$

Note. $R^{2}=.22, F(4,795)=54.80, p<.001 . b$ represents unstandardized regression weights.

Beta indicates standardized regression weights. $L L$ and $U L$ indicate the lower and upper limits of a confidence interval, respectively. ${ }^{\circ} \mathrm{C}=$ Mean daily temperature in degrees Celsius. $\mathrm{RCI}=$ Mean centered mean of Religious Commitment Inventory items.

Figure 1

(a) Partial regression scatterplot of women's skin exposure in photograph of what women wore to the laboratory (Y-axis) and women's religiosity scores (X-axis).

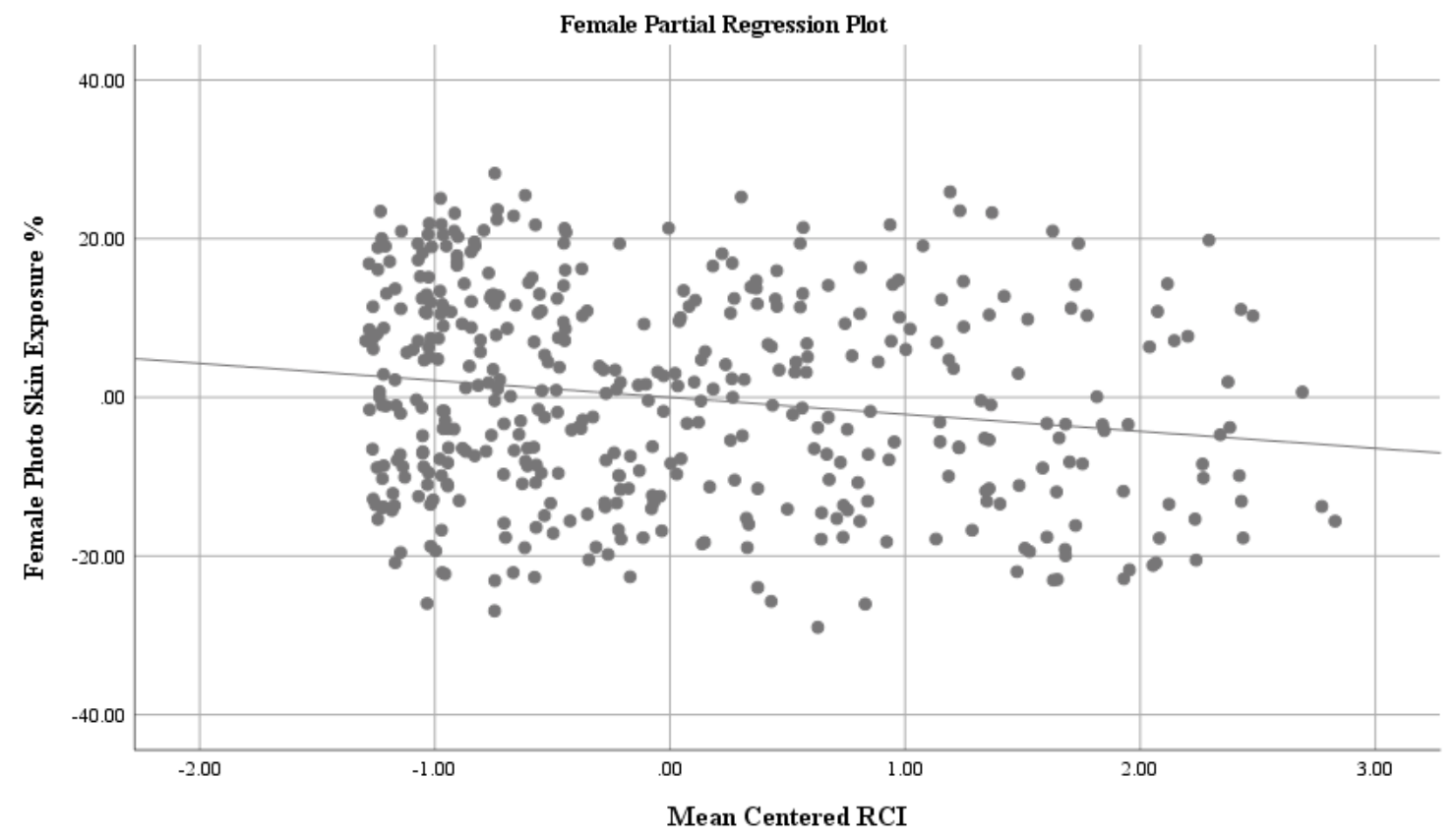

(b) Partial regression scatterplot of men's skin exposure in photograph of what men wore to the laboratory (Y-axis) and men's religiosity scores (X-axis). 


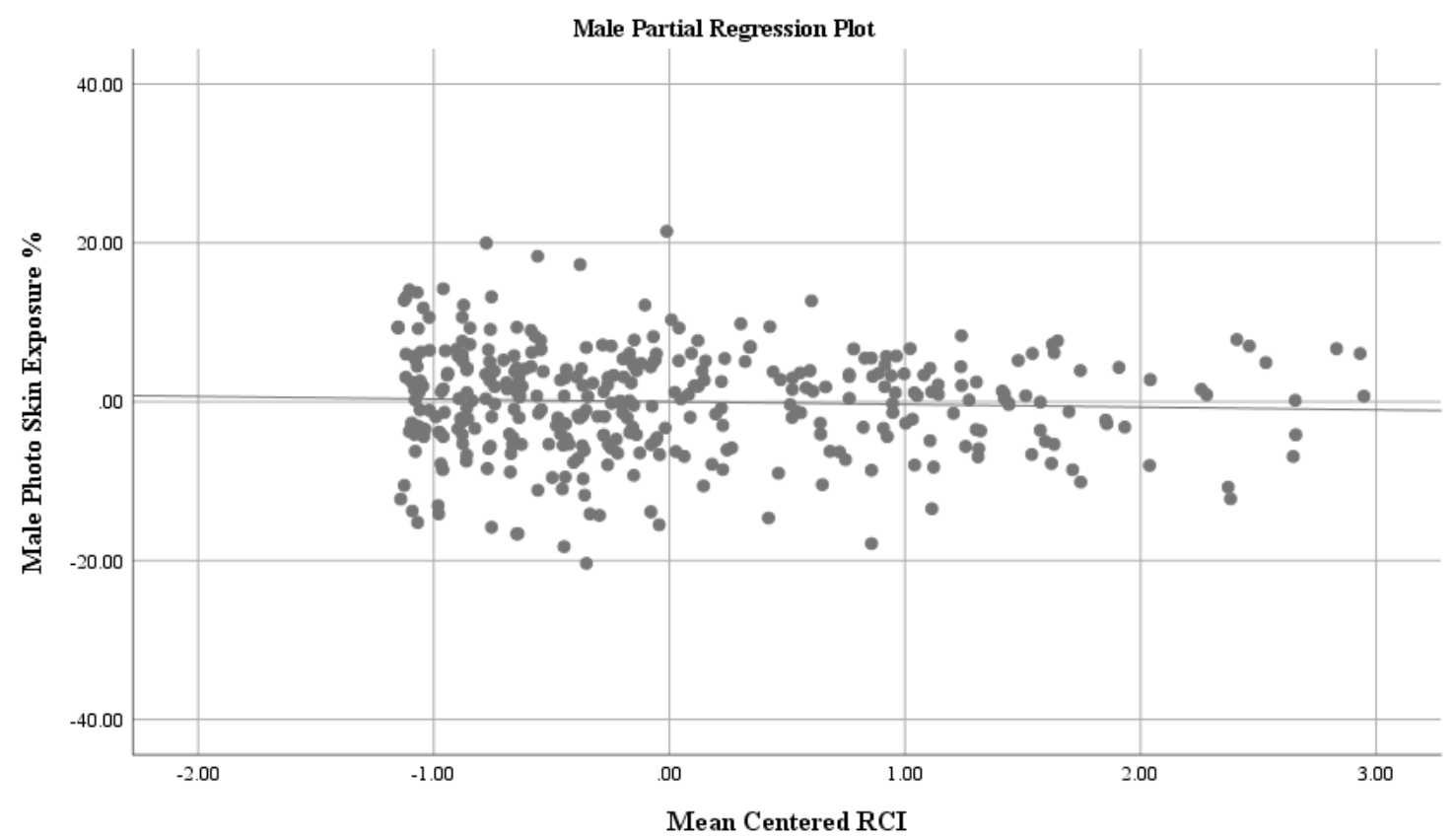

\section{Experimental Manipulation of Illustration Provocativeness of Dress via Religion}

For women, $F(2,437)=4.29, p=0.01$, but not for men, $F(2,369)=0.08, p=0.92$, we found evidence for writing task condition assignment group differences in illustration skin exposure. We thus conducted a two-stage hierarchical multiple regression analysis to predict illustration skin exposure from photograph skin exposure, mean daily temperature, sex, and religiosity scores. Photograph skin exposure, mean daily temperature, sex (dummy-coded with women as the reference group), religiosity scores, and the religiosity scores by sex interaction were entered in the first block. The two dummy-coded condition assignment variables, the two sex by condition assignment interactions, and the two religiosity score by condition assignments interactions were entered in the second block (see Table 2).

\section{Table 2}

Two-stage regression results using illustrations of what participants would wear to a party later that night as the criterion. 
$95 \%$ CI for $b$

\begin{tabular}{|c|c|c|c|c|c|c|c|c|}
\hline & Predictor & $b$ & $S E$ & Beta & $t$ & $p$ & $L L$ & $U L$ \\
\hline \multirow[t]{7}{*}{1} & Constant & 37.26 & 4.37 & & 8.52 & $<0.001$ & 28.67 & 45.84 \\
\hline & Photo Skin & 0.22 & 0.04 & 0.15 & 5.82 & $<0.001$ & 0.15 & 0.29 \\
\hline & Exposure & & & & & & & \\
\hline & ${ }^{\circ} \mathrm{C}$ & 0.19 & 0.09 & 0.06 & 2.22 & 0.03 & 0.02 & 0.36 \\
\hline & Sex & -23.10 & 0.86 & -0.68 & -27.03 & $<0.001$ & -24.78 & -21.43 \\
\hline & $\mathrm{RCI}$ & -1.48 & 0.52 & -0.09 & -2.85 & $<0.001$ & -2.50 & -0.46 \\
\hline & Sex by RCI & 1.63 & 0.81 & 0.06 & 2.02 & 0.04 & 0.04 & 3.21 \\
\hline
\end{tabular}

Note. Model $1 R^{2}=0.56, F(5,790)=204.38, p<0.001 . b$ represents unstandardized

regression weights. Beta indicates standardized regression weights. $L L$ and $U L$ indicate the lower and upper limits of a confidence interval, respectively. ${ }^{\circ} \mathrm{C}=$ Mean daily temperature in degrees Celsius. $\mathrm{RCI}=$ Mean centered mean of Religious Commitment Inventory items.

\begin{tabular}{lrlccccc}
\hline 2 Constant & 38.75 & 4.50 & & 8.61 & $<0.001$ & 29.92 & 47.59 \\
Photo Skin & 0.21 & 0.04 & 0.15 & 5.58 & $<\mathbf{0 . 0 0 1}$ & 0.14 & 0.29 \\
Exposure & & & & & & & \\
o C & 0.20 & 0.09 & 0.06 & 2.27 & $\mathbf{0 . 0 2}$ & 0.03 & 0.36 \\
Sex & -24.71 & 1.44 & -0.73 & -17.18 & $<\mathbf{0 . 0 0 1}$ & -27.54 & -21.89 \\
RCI & -0.64 & 0.81 & -0.04 & -0.80 & 0.43 & -2.22 & 0.94 \\
Sex by RCI & 1.38 & 0.81 & 0.05 & 1.69 & 0.09 & -0.22 & 2.97 \\
Religious & -3.15 & 1.32 & -0.09 & -2.39 & $\mathbf{0 . 0 2}$ & -5.73 & -0.56
\end{tabular}

Condition 
$\begin{array}{llllllll}\text { Secular } & -1.88 & 1.36 & -0.05 & -1.38 & 0.17 & -4.56 & 0.80\end{array}$

Condition

Sex by

1.93

0.05

1.26

0.21

$-1.36$

6.22

Religious

Condition

Sex by

$\begin{array}{ll}1.82 & 2.02\end{array}$

$0.04 \quad 0.90$

0.37

$-2.14$

5.77

Secular

Condition

RCI by

$-1.91 \quad 0.97$

$-0.07$

$-1.96$

0.05

$-3.81$

0.00

Religious

Condition

RCI by $-0.19$

0.99

$-0.01$

$-0.19$

0.85

$-2.12$

1.75

Secular

Condition

Note. Model $2 R^{2}=0.57, F(11,784)=94.47, p<0.001 . b$ represents unstandardized regression weights. Beta indicates standardized regression weights. $L L$ and $U L$ indicate the lower and upper limits of a confidence interval, respectively. ${ }^{\circ} \mathrm{C}=$ Mean daily temperature in degrees Celsius. $\mathrm{RCI}=$ Mean centered mean of Religious Commitment Inventory items.

In the first block, significant effects of photograph skin exposure, mean daily temperature, sex, and religiosity scores indicated that for women, as religiosity increased, illustration skin exposure decreased (see Figure 2a). A significant sex by religiosity score interaction indicated that no such relationship between religiosity scores and skin exposure 
existed for men (see Figure 2b). Together, these variables accounted for about $56 \%$ of the variance in illustration skin exposure. The second set of independent variables - the two dummycoded condition assignment variables, the two sex by condition assignment interactions, and the two religiosity score by condition assignment interactions explained an additional $1 \%$ percent of the variation in illustration skin exposure, $R^{2}$ change $=0.01, F(6,784)=1.85, p=0.09$. Together, these variables account for $57 \%$ of the variance in illustration skin exposure.

\section{Figure 2}

(a) Partial regression scatterplot of women's skin exposure in illustrations of what women would wear to a party later that night (Y-axis) and women's religiosity scores (X-axis).

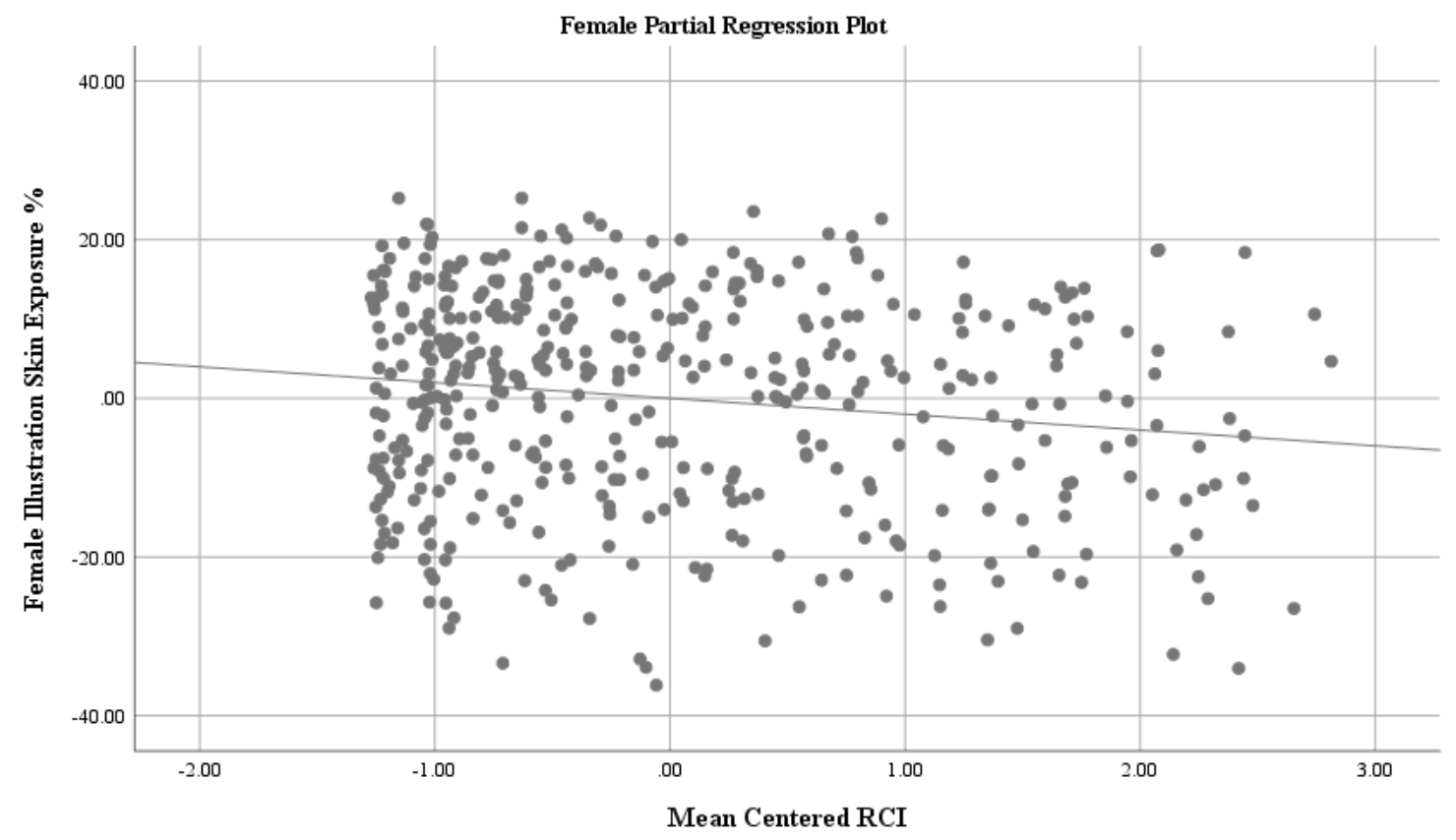

(a) Partial regression scatterplot of men's skin exposure in illustrations of what men would wear to a party later that night (Y-axis) and men's religiosity scores (X-axis). 


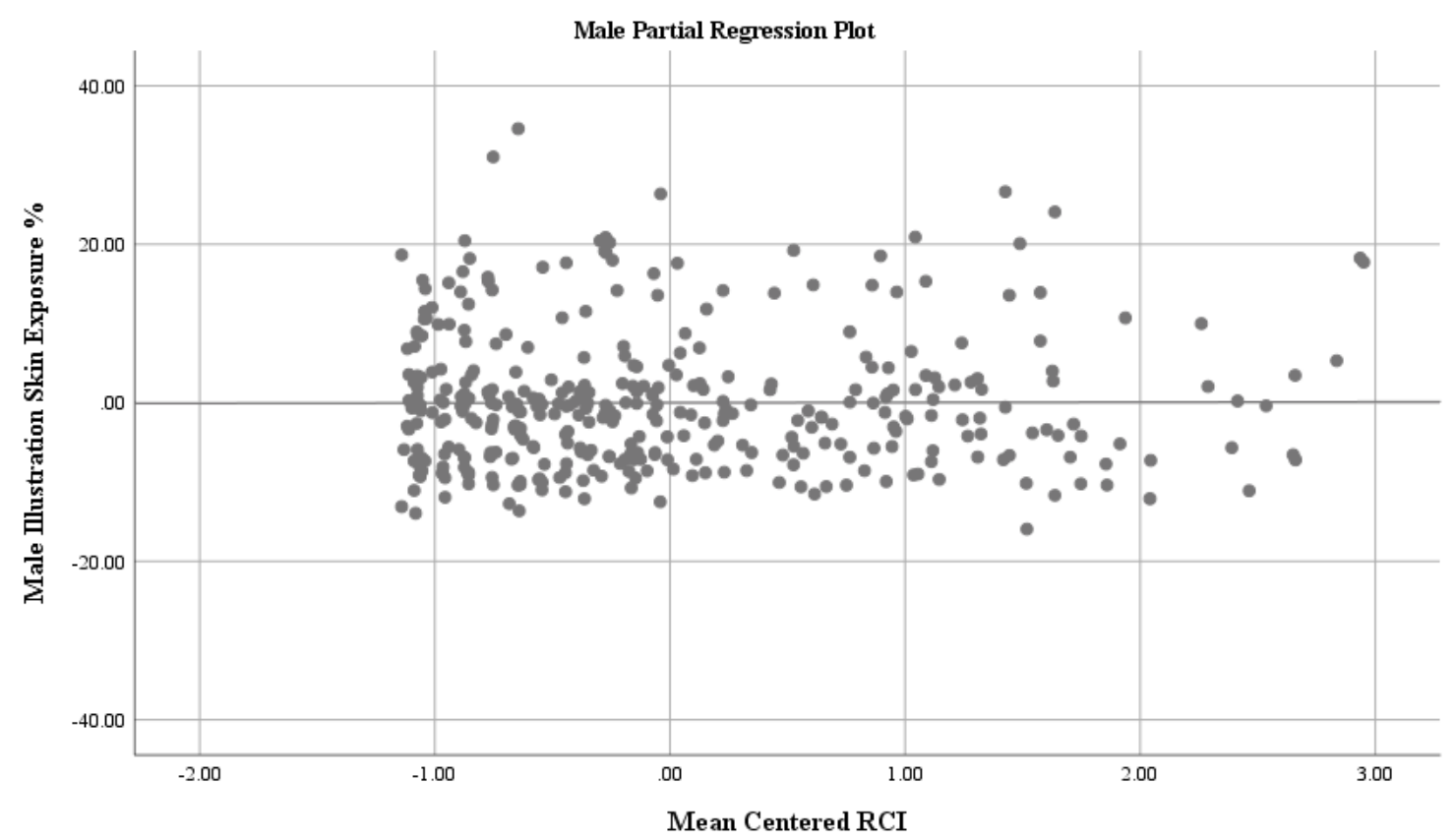

In the presence of the original independent variables entered in the first block as well as the six additional variables added in the second block, there remained no relationship between religiosity scores and skin exposure. However, the significant effects in block two indicated that women in the religious writing task condition exposed less skin relative to women in the control writing task condition, and that women in the secular writing task condition did not expose less skin than women in the control writing task condition. In addition to the effect of the religious writing task condition assignment, there was a religiosity score by religious condition assignment interaction: The religious writing task condition assignment was more effective in reducing skin exposure for highly religious participants than it was for less religious participants (see Figure 3).

\section{Figure 3}

(a) Partial regression scatterplot of women's skin exposure in illustrations of what women would wear to a party later that night (Y-axis) and women's religiosity scores (X-axis) among women in the religious writing task condition. 


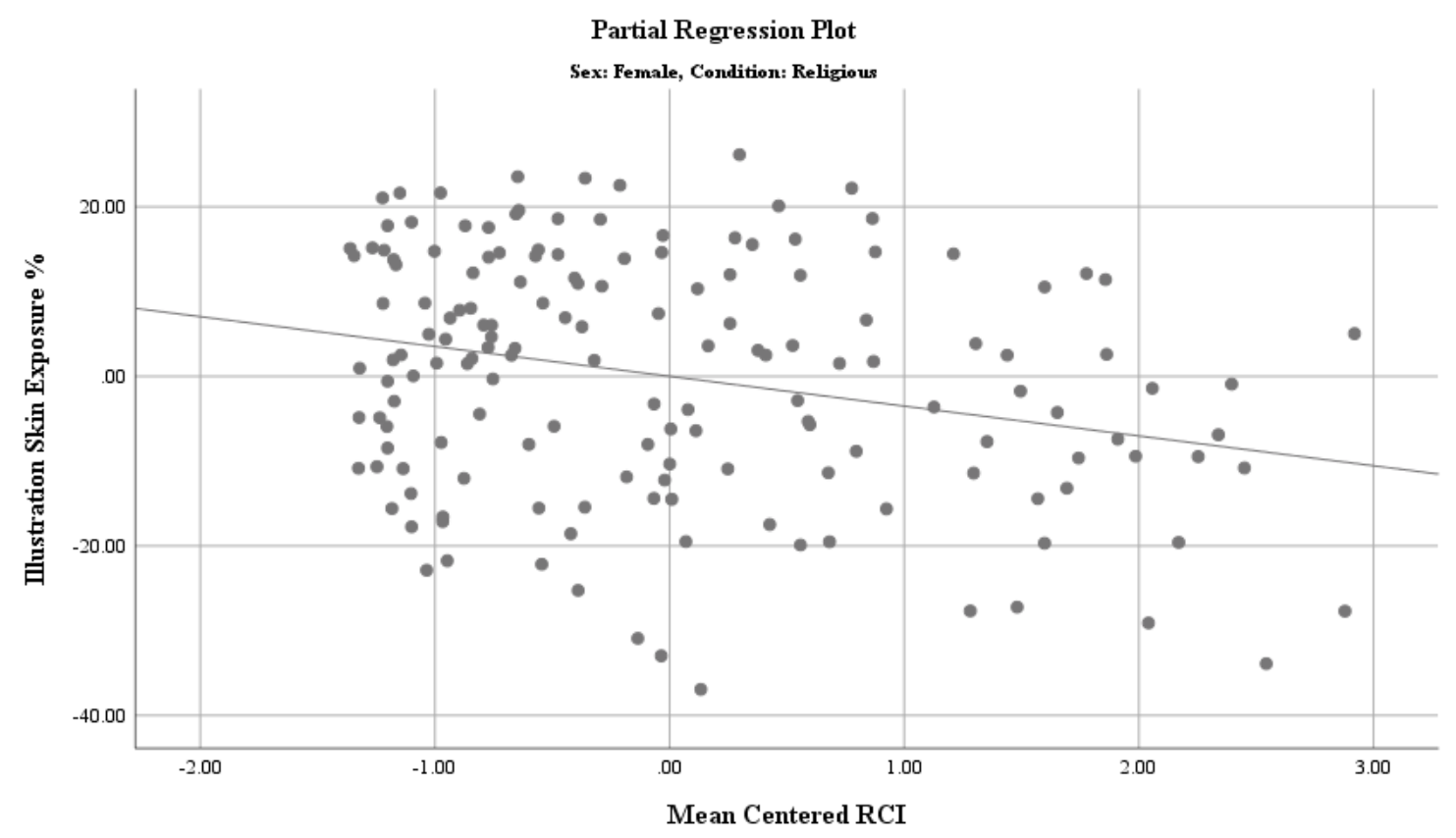

(b) Partial regression scatterplot of men's skin exposure in illustrations of what men would wear to a party later that night (Y-axis) and men's religiosity scores (X-axis) among men in the religious writing task condition.

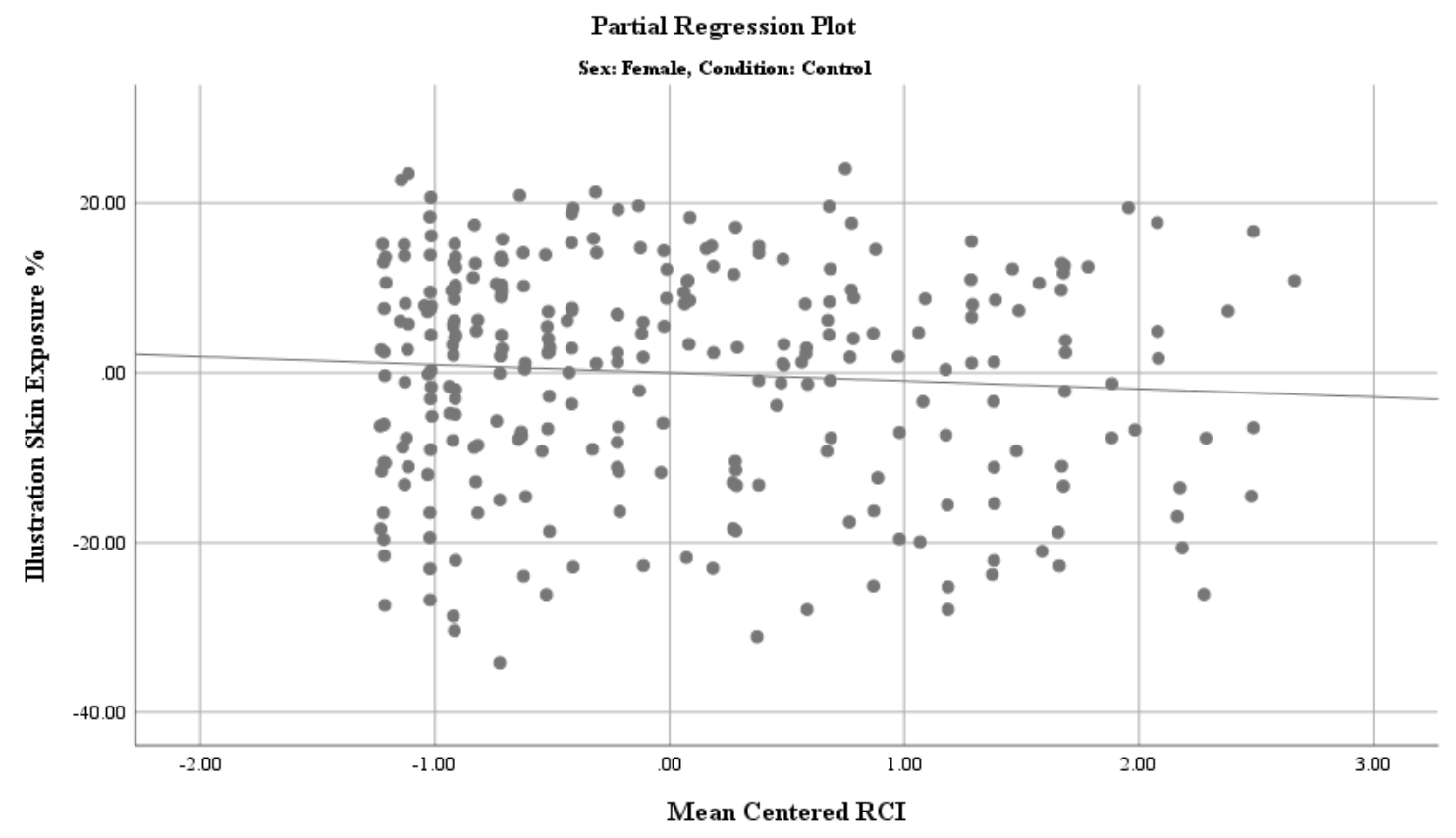




\section{Discussion}

On the premise that provocativeness of dress (POD) may be a characteristic associated with women's (but not with men's) short-term mating strategies, we tested whether women's baseline religiosity predicts POD. To accomplish this, we tested whether participants' religiosity was negatively correlated with their skin exposure in photographs of what they wore to the laboratory, controlling for mean daily temperature. Religiosity was indeed associated with women's POD: Women who classified themselves as highly religious exposed less skin in their day-to-day lives. The same was not true of men.

On the premise that religious stimuli might down-regulate characteristics associated with short-term mating strategies in women, we also tested whether women who were exposed to religious stimuli would expose less skin in a hypothetical situation. We predicted that women (but not men) who were randomly assigned to complete a religious writing task would illustrate less skin exposure when asked what they would wear to a hypothetical social gathering. In line with our prediction, we found that women who wrote about their God and religion exposed less skin than those who were not in the religious writing task condition. The same was not true of men. We also found a religiosity by religious condition assignment interaction, whereby participants in the religious writing task condition, relative to the control writing task condition, exposed less skin if they were more religious. This indicated that perhaps religious participants view POD in as an important indicator of sexual morality, more so than their less religious peers, and these thoughts are activated in religious men in the same why that they are activated in women.

\section{Limitations}


The findings here should be interpreted with several limitations in mind. First, the participants in this study were college students and college students are atypical with regard to their views on religion and sex (Beckwith \& Morrow, 2005; Pascarella \& Terenzini, 1991). College students tend to be less religiously committed and more sexually unrestricted than older samples (Beckwith \& Morrow, 2005; Pascarella \& Terenzini, 1991). Subsequently, the results obtained here are perhaps not generalizable and sampling from a college population may have biased results in unknown ways. Second, the experiment described here took place in a laboratory and required participants to indicate what they would wear to a gathering with attractive members of the opposite sex in attendance — we did not directly measure what participants actually wore to social gatherings with peers from their mating pool. The artificial nature of the laboratory task most likely limited the external validity of the results obtained here, as participants may have under- or over-reported the degree to which they typically expose skin in certain situations.

\section{Future Directions}

To confirm the finding that religion influences women's POD, replicating these findings in a non-college population would be ideal. Future studies should also consider using a life history perspective and assess changes in POD as participants age: Individuals promulgate different mating strategies at different ages, so perhaps POD fluctuates with age, depending on whether a restricted or unrestricted strategy best suits the individual (Kaplan \& Gangestad, 2004). Furthermore, to confirm that religion causes women to indicate that they would dress modestly in preparation for a social gathering, a more direct measure of women's skin exposure at social gatherings, rather than indirect measures of what women would hypothetically wear, would be useful. 
Our attempt to experimentally manipulate women's provocativeness of dress via religion was successful—random assignment to a religious writing task condition influenced women's POD in a reliable way. Studies attempting to experimentally manipulate human behavior, particularly via priming, are difficult to conduct and replicate (Carlin \& Standing, 2013; Doyen, Klein, Pichon, \& Cleeremans, 2012; Hone \& McCullough, 2014; Pashler, Coburn, \& Harris, 2012), and require large samples (Hone, McCauley, Pedersen, Carter, \& McCullough; 2018, July 17) perhaps because priming methods rely on activating religious (or other socially relevant) salience implicitly or subliminally. For the purposes of this experiment, instead of administering a prime with subtle cues to religion, we used an explicit religious writing task. Because we found an effect of religion on POD when using an explicit writing task, perhaps future studies on the causal relationship between religion and human behavior via use of explicit writing tasks, rather than implicit priming tasks, would be a fruitful avenue of research.

Finally, this work has a number of implications for understanding risk behaviors and sexual health. For example, female provocativeness of dress is a cue hypothesized to be misperceived by men as indicative of a woman's sexual interest (Treat, Hinkel, Smith, \& Viken, 2016). Indeed, several studies have shown a link between rape supportive attitudes as well as sexual aggression perpetration and reliance on a woman's POD, rather than her affect (Treat, Church, \& Viken, 2017). The methods developed here for assessing POD are perhaps applicable to future studies of antecedents of sexual aggression. Furthermore, the results here suggest that not only do individual difference in religiosity predict POD in day-to-day life, but that exposure to religious stimuli decreases later POD, especially among women. Our increased understanding of predictors of POD, like religiosity and religious stimuli, may be useful in understanding negative outcomes related to variation in POD. 


\section{Conclusion}

These findings comport well with previous findings that sexual morality and religiosity are closely linked and reveal that religiosity is associated with women's, but not men's, provocativeness of dress. Future studies designed to confirm the relationship between women's religiosity and provocativeness of dress would benefit from sampling from a population with representatives from multiple and diverse religions and levels of religiosity, as well as more precise measures of skin exposure during less artificial settings. Furthermore, the use of explicit writing tasks, rather than implicit priming tasks might enable researchers to better detect effects of religion on human behavior. Finally, future studies that assess changes in provocativeness of dress and religiosity as people age might be a fruitful line of research and shed light on how religiosity might down-regulate sexually selected, characteristically female behaviors throughout a woman's life. 


\section{References}

Aalsma, M. C., Woodrome, S. E., Downs, S. M., Hensel, D. J., Zimet, G. D., Orr, D. P., \& Fortenberry, J. D. (2013). Developmental trajectories of religiosity, sexual conservatism and sexual behavior among female adolescents. Journal of Adolescence, 36(6), 1193-1204. https://doi.org/10.1016/j.adolescence.2013.08.005

Ahrold, T. K., Farmer, M., Trapnell, P. D., \& Meston, C. M. (2011). The relationship among sexual attitudes, sexual fantasy, and religiosity. Archives of Sexual Behavior, 40(3), 619630. https://doi.org/10.1007/s10508-010-9621-4

Almanac, O. F. (2015). Weather History: Past Weather Reports. Retrieved from http://www.almanac.com/weather/history/FL/Coral+Gables

Archer, J. (2009). Does sexual selection explain human sex differences in aggression? Behavioral and Brain Sciences, 32, 249-311. https://doi.org/10.1017/S0140525X09990951

Beckwith, H. D., \& Morrow, J. A. (2005). Sexual attitudes of college students: The impact of religiosity and spirituality. College Student Journal, 39(2), 357-367.

Billingsley, J., Gomes, C., \& McCullough, M. E. (2018). Implicit and explicit influences of religious cognition on Dictator Game transfers. Royal Society Open Science, 5, 170238. https://doi.org/10.1098/rsos.170238

Buss, D. M., \& Schmitt, D. P. (1993). Sexual strategies theory: An evolutionary perspective of human mating. Psychological Review, 100(2), 204-232.

Carlin, S. P., \& Standing, L. G. (2013). Is intelligence enhanced by letter priming? A failure to replicate the results of Ciani and Sheldon (2010). Psychological Reports, 112(2), 533-544. https://doi.org/10.2466/04.03.PR0.112.2.533-544

Daly, M., \& Wilcon, M. (2005). Carpe diem: Adaptation and devaluing the future. The Quarterly 
Review of Biology, 80(1), 55-60.

Davis, D. (2017). Examining the Potential Relationship between Religious Identity, Ethnic Identity, and Attitudes towards Sexualized Clothing of Women Living in the United States. Retrieved from http://ir.obihiro.ac.jp/dspace/handle/10322/3933

Doyen, S., Klein, O., Pichon, C.-L., \& Cleeremans, A. (2012). Behavioral priming: It's all in the mind, but whose mind? PloS One, 7(1), e29081. https://doi.org/10.1371/journal.pone.0029081

Durante, K. M., Li, N. P., \& Haselton, M. G. (2008). Changes in women's choice of dress across the ovulatory cycle: Naturalistic and laboratory task-based evidence. Personality \& Social Psychology Bulletin, 34(11), 1451-1460. https://doi.org/10.1177/0146167208323103

Grammer, K., Renninger, L., \& Fischer, B. (2004). Disco clothing, female sexual motivation, and relationship status: Is she dressed to impress? Journal of Sex Research, 41(1), 66-74.

Hall, D. L., Cohen, A. B., Meyer, K. K., Varley, A. H., \& Brewer, G. A. (2015). Costly signaling increases trust, even across religious affiliations. Psychological Science, 26(9), 1368-1376. https://doi.org/10.1177/0956797615576473

Hawkes, K. (1991). Showing off. Ethology and Sociobiology, 12, 29-54. https://doi.org/10.1016/0162-3095(91)90011-E

Hone, L. S. E. (2015). Does Religion Promote Modesty? Correlational and Experimental Tests. Open Access Dissertations, 1473. Retrieved from https://scholarlyrepository.miami.edu/oa_dissertations/1473

Hone, L. S. E., \& McCullough, M. E. (2014). Does religious cognition really down-regulate hand grip endurance in men? A failure to replicate. Evolution and Human Behavior, 36(2), 81-85. https://doi.org/10.1016/j.evolhumbehav.2014.08.007 
Hone, L. S. E., McCauley, T. G., Pedersen, E. J., \& McCullough, M. E. (2018, July 17). The Sex Premium in Religiously Motivated Moral Judgment. https://doi.org/10.31234/osf.io/xpz5h

Kaplan, H. S., \& Gangestad, S. W. (2004). Life history theory and evolutionary psychology. In The Handbook of Evolutionary Psychology (pp. 1-46). John Wiley \& Sons Inc.

Kenrick, D. T., \& Keefe, R. C. (1992). Age preferences in mates reflect sex differences in human reproductive strategies. Behavioral and Brain Sciences, 15(1), 75-91. https://doi.org/10.1017/S0140525X00067595

Kirby, K. N., \& Maraković, N. N. (1996). Delay-discounting probabilistic rewards: Rates decrease as amounts increase. Psychonomic Bulletin \& Review, 3(1), 100-104. https://doi.org/10.3758/BF03210748

Li, Y. J., Cohen, A. B., Weeden, J., \& Kenrick, D. T. (2010). Mating competitors increase religious beliefs. Journal of Experimental Social Psychology, 46(2), 428-431. https://doi.org/10.1016/j.jesp.2009.10.017

Little, M. A., \& Johnson, B. R. (1986). Grip strength, muscle fatigue, and body composition in nomadic Turkana pastoralists. American Journal of Physical Anthropology, 69, 335-344. https://doi.org/10.1002/ajpa.1330690306

McCullough, M. E., Carter, E. C., DeWall, C. N., \& Corrales, C. M. (2012). Religious cognition down-regulates sexually selected, characteristically male behaviors in men, but not in women. Evolution and Human Behavior, 33(5), 562-568. https://doi.org/10.1016/j.evolhumbehav.2012.02.004

McCullough, M. E., Swartwout, P., Shaver, J. H., Carter, E. C., \& Sosis, R. (2016). Christian religious badges instill trust in Christian and non-Christian perceivers. Psychology of Religion and Spirituality, 8(2), 149-163. https://doi.org/10.1037/rel0000045 
McKay, R., Efferson, C., Whitehouse, H., \& Fehr, E. (2011). Wrath of God: Religious primes and punishment. Proceedings of the Royal Society B: Biological Sciences, 278, 1858-1863. https://doi.org/10.1098/rspb.2010.2125

Moon, J. W., Krems, J. A., \& Cohen, A. B. (2018). Religious People Are Trusted Because They Are Viewed as Slow Life-History Strategists. Psychological Science, 29(6), 947-960. https://doi.org/10.1177/0956797617753606

Moon, J. W., Krems, J. A., Cohen, A. B., \& Kendrick, D. (2019). Is nothing sacred? Religion, sex, and reproductive strategies. Current Directions in Psychological Science. https://doi.org/10.1177/0963721419838242

Pascarella, E. T., \& Terenzini, P. T. (1991). How college aflects students (San Franci). JosseyBass.

Pashler, H., Coburn, N., \& Harris, C. R. (2012). Priming of social distance? Failure to replicate effects on social and food judgments. PLOS One, 7(8), e42510. https://doi.org/10.1371/journal.pone.0042510

Pawlowski, B., Atwal, R., \& Dunbar, R. I. M. (2008). Sex differences in everyday risk-taking behavior in humans. Evolutionary Psychology, 6, 29-42.

Pines, A. M. (1998). A prospective study of personality and gender differences in romantic attraction. Personality and Individual Differences, 25(1), 147-157.

Provost, M. P., Troje, N. F., \& Quinsey, V. L. (2008). Short-term mating strategies and attraction to masculinity in point-light walkers. Evolution and Human Behavior, 29(1), 65-69. https://doi.org/10.1016/j.evolhumbehav.2007.07.007

Randolph-Seng, B., \& Nielsen, M. E. (2007). Honesty: One effect of primed religious representations. International Journal for the Psychology of Religion, 17(4), 303-315. 
https://doi.org/10.1080/10508610701572812

Schmitt, D. P., \& Fuller, R. C. (2015). On the varieties of sexual experience: Cross-cultural links between religiosity and human mating strategies. Psychology of Religion and Spirituality, 7(4), 314-326. https://doi.org/10.1037/re10000036

Shariff, A. F., \& Norenzayan, A. (2007). God is watching you. Psychological Science, 18(9), 803-809.

Shih, Y.-C. (2007). Glove and gender effects on muscular fatigue evaluated by endurance and maximal voluntary contraction measures. Human Factors, 49, 110-119. https://doi.org/10.1518/001872007779598091

Silverman, I. W. (2003). Gender differences in delay of gratification: A meta-analysis. Sex Roles, $49,451-463$.

Strassmann, B. I., Kurapati, N. T., Hug, B. F., Burke, E. E., Gillespie, B. W., Karafet, T. M., \& Hammer, M. F. (2012). Religion as a means to assure paternity. Proceedings of the National Academy of Sciences, 109(25), 9781-9785. https://doi.org/10.1073/pnas.1110442109

Tan, J. H. W., \& Vogel, C. (2008). Religion and trust: An experimental study. Journal of Economic Psychology, 29, 832-848. https://doi.org/10.1016/j.joep.2008.03.002

Treat, T. A., Church, E. K., \& Viken, R. J. (2017). Effects of gender, rape-supportive attitudes, and explicit instruction on perceptions of women's momentary sexual interest. Psychonomic Bulletin \& Review, 24(3), 979-986.

Treat, T. A., Hinkel, H., Smith, J. R., \& Viken, R. J. (2016). Men’s perceptions of women’s sexual interest: Effects of environmental context, sexual attitudes, and women's characteristics. Cognitive Research: Principles and Implications, Vol. 1, pp. 1-13. https://doi.org/10.1186/s41235-016-0009-4 
Twenge, J. M., Sherman, R. A., \& Wells, B. E. (2015). Changes in American adults' sexual behavior and attitudes, 1972-2012. Archives of Sexual Behavior, 44(8), 2273-2285. https://doi.org/10.1007/s10508-015-0540-2

Weeden, J., Cohen, A. B., \& Kenrick, D. T. (2008). Religious attendance as reproductive support. Evolution and Human Behavior, 29(5), 327-334. https://doi.org/10.1016/j.evolhumbehav.2008.03.004

Weeden, J., \& Kurzban, R. (2013). What predicts religiosity? A multinational analysis of reproductive and cooperative morals. Evolution and Human Behavior, 34, 440-445. https://doi.org/10.1016/j.evolhumbehav.2013.08.006

Wilson, M., \& Daly, M. (2004). Do pretty women inspire men to discount the future? Proceedings of the Royal Society B, 271, S177-S179. https://doi.org/10.1098/rsbl.2003.0134

Worthington, E. L., Wade, N. G., Hight, T. L., Ripley, J. S., McCullough, M. E., Berry, J. W., ... O’Connor, L. (2003). The Religious Commitment Inventory--10: Development, refinement, and validation of a brief scale for research and counseling. Journal of Counseling Psychology, 50(1), 84-96. https://doi.org/10.1037/0022-0167.50.1.84

Wright, P. J. (2013). U.S. males and pornography, 1973-2010: Consumption, predictors, correlates. Journal of Sex Research, 50(1), 60-71. https://doi.org/10.1080/00224499.2011.628132 